\title{
Biodegradation of Organochlorine Pesticides by Means of Pectobacterium Wasabiae
}

\section{El-Sayed B Belal ${ }^{1}$, Nagwa M Sidkey ${ }^{2}$, Waseem A Gad ${ }^{3 *}$ and Seham S El- Gendy $^{2}$}

${ }^{1}$ Agricultural Botany Department, Agricultural Microbiology, Faculty of Agriculture, Kafrelsheikh University, Egypt

${ }^{2}$ Botany and Microbiology Department, Faculty of Science, Al-Azhar University, Egypt

${ }^{3}$ Central Laboratory, Kafr El-Sheikh Company for Water and Wastewater, Egypt

\section{Review Article}

Volume 4 Issue 1

Received Date: March 02, 2020

Published Date: March 27, 2020

DOI: $10.23880 /$ ijoac-16000183

*Corresponding author: Waseem A Gad, Central Laboratory, Kafr El-Sheikh Company for Water and Wastewater, Kafr El-Sheikh, Egypt, Tel: +201015119474; Email: withyou_2010@yahoo.com

\section{Abstract}

Water pollution is a major cause of global concern as it leads to the onset of numerous fatal diseases which are responsible for the death of 14000 people. The Aquatic systems contamination by pesticides is one of the most serious problems that might face the environment and organisms as a whole. One of the safest potential techniques in the remediation of chemically contaminated water is the biological remediation. Bioremediation is one of the friendliest environmental and cost-effective methods for the decontamination and detoxification of pesticides contaminated water. From this regard, this work presents the investigation of the biodegradation potential of 17 tested organochlorine pesticides by some bacterial isolates. Moreover, the remaining toxicity of the 17 tested organochlorine pesticides with tested strains was evaluated to confirm the complete removal of any toxic materials. The testing of the isolated bacteria for the biodegradation capability showed that all the isolated microorganisms having remarkable variation in the biodegradation process which could be detected in the aqueous media containing the active ingredients of the 17 OCPs by two approaches, the analysis of the OCP residues at the end of the incubation period and measuring the bacterial growth in terms of the total viable count and the optical density OD. The bacterial isolate 03 presented the great degradation value as well as high total viable count and OD measurements. According to the morphological, biochemical and 16S RNA, the bacterial isolate was identified as Pectobacterium wasabiae CFBP 3304. There is no remaining toxicity of the 17 OCPs detected in aqueous media previously treated with Anabaena sp. The study findings strongly support that bioremediation by Pectobacterium wasabiae CFBP 3304 to be a promising approach for the biodegradation and removal of OCPs residues in an aqueous system.

Keywords: Biodegradation, Organochlorinated pesticides, Kafr El-sheikh, Pectobacterium, Optical density, Aqueous system, Viable count

\section{Introduction}

Water is a multi-dimensional issue and a prerequisite for achieving human security, from the individual to the international level. Water pollution is a serious problem for all the world and it is considered to be one of the most harmful problems affecting Egypt. Water pollution is a major cause of global concern as it leads to the onset of numerous fatal diseases which are responsible for the death of over 14,000 people every day [1].

The Aquatic systems contamination by pesticides is one of the most serious problems that might face the environment and organisms as a whole. The intensively cultivated agricultural areas are significant sources of surface water contamination by pesticides via spray drift and/or runoff 
[2]. According to the world health organization (WHO), $80 \%$ diseases are water borne. Drinking water in various countries does not meet WHO standards [3] 3.1\% deaths occur due to the unhygienic and poor quality of water [4]. Health risk associated with polluted water includes different diseases such as respiratory disease, cancer, diarrheal disease, neurological disorder and cardiovascular disease [5].

In modern agriculture practices, the extensive use of pesticides is very frequent to fulfill higher yield requirements. Millions of tons of pesticides are applied annually all over the globe, which covers the billions of dollars" market. The expenditures on pesticides were 35.8 billion in 2006 which rose to 39.4 billion US dollars in 2007. The extensive need to produce a greater quantity and quality of food using pest control resulted in the intensive use of pesticides over the last 50 years [6]. Control of a wide range of human and livestock disease vectors thus reducing the number of infected individuals and deaths accompanied by the prevention of international disease spread is among critical obvious benefits of broad pesticide use [7].

The entry of Pesticides into Water Systems can occur through two fundamental processes, through runoff or leaching. As a result of reaching and consumption of pesticide-contaminated water by humans, this can lead to many dangerous effects. The application of pesticides in the agricultural field can result in contamination of surface water, which in turn raised risk for the ecosystem as well as the drinking water quality [8].

Pesticide contamination of surface waters has been well documented worldwide and constitutes a major issue that gives rise to concerns at local regional, national and global scales [9]. Contamination of water by pesticides is widespread, more than 90 percent of water and fish samples from all streams contained one, or more often, several pesticides [10]. The contamination by organochlorine pesticides (OCPs) is usually focused on due to their toxicity and persistence in the environment for long periods. Organochlorine pesticides are Stable compounds that are too persistent in the environment and tend to accumulate in fatty tissue [11]. Its main use is in the eradication of disease vectors such as malaria, dengue. They are also used in the cultivation of grapes, lettuce, tomato, alfalfa, corn, rice, sorghum, cotton, and wood, for preservation. Some organochlorine pesticides (OCPs) such as DDT and Dieldrin are mutinous, remaining in the environment, and are known to accumulate into food chains decades after their application to soil [12]. The hazardous nature of organochlorines was explained by citing different examples. The menace caused by endosulfan is of great concern. Endosulfan remains in the environment for long periods and bio-accumulates in plants and animals which leads to contamination of food consumed by humans [13]. It affects mainly the central nervous system and was found to have higher acute inhalation toxicity than dermal toxicity. Gastrointestinal absorption of endosulfan is very high [14]. Organochlorines act as endocrine-disrupting chemicals (EDCs) by interfering with the molecular circuitry and function of the endocrine system [15]. Many of the organochlorine molecules are carcinogens and neurotoxic [16].

Waste-water treatment is becoming even more important in the light of diminishing water resources, increasing industrial, domestic and agriculture water usage and consequently waste-water disposal and its costs along with stricter discharge regulations that have lowered permissible contaminant levels in waste streams.

The purpose of wastewater treatment is to remove the contaminants from water so that the treated water meets acceptable quality standards. The quality standards usually depend upon whether the water will be reused or discharged into a receiving stream. There are many techniques for remediation or removal of these toxic pesticides; these include chemical decomposition, photochemical decomposition, volatilization, plant uptake, absorption, and microbial decomposition. The traditional methods of pesticide removal depended upon incineration and landfills, which produced secondary pollution complications due to the leakage of pesticides into the neighboring soil and water supplies and the production of highly toxic by-product emissions. Moreover, these methods are very costly and demand large quantities of energy. The biochemical and molecular methods of pesticide degradation by microorganisms have been well documented [17,18]. Molecular techniques contribute a major role in the current progress in the bioremediation of xenobiotic including pesticides. Among the molecular approaches is the construction of DNA probes, isolation of plasmid DNA to explore the efficient genes implicated in isolation of plasmid DNA catabolism of xenobiotics and to study the genetic diversity of environmentally significant microbes [19].

Biological techniques that are cheaper and easier to operate have become the focus in recent studies of chlorinated pesticide degradation. Bioremediation is one of the most trusted environmental and cost-effective methods for the decontamination and detoxification of pesticidecontaminated water. Microorganisms can use a variety of xenobiotic compounds including pesticides for their growth, mineralization, and detoxification of these compounds represented a very exceptional form of biodegradation called bioremediation of pesticides [20]. Bioremediation is 
an accepted technology for accelerating the rate of cleanup of contaminated water.

Bacterial biodegradation of pesticides. has a vital advantage of due to the diversity, wide distribution, and adaptation of variable metabolic pathways. Numerous bacteria were found to be able to co-metabolically metabolize DDT by dechlorination to DDD under anaerobic conditions [21]. Biodegradation of dieldrin and endrin was reviewed in 1982 [22]. Numerous microorganisms and have been isolated and characterized for their ability to metabolize DDTs, notably from contaminated sites [22-26]. However, after remediation toxicity assessment is needed, firstly, to provide valuable and complementary information to the compound analysis. Secondly, the major advantage of toxicity tests is the direct assessment of the potential hazard to the environmental system by both the original pollutants and its metabolites [27].

In that regard, this study aims to isolate and identify different bacterial microbes for bioremediation of a set of different 17 organochlorinated pesticides (OCPs) in an aquatic system, to evaluate the degradation potential of the isolated bacteria against the different 17 OCPs, and finally, to confirm the complete detoxification the tested OCPs by measuring the toxicity of the treated solution against a sensitive target.

\section{Materials and Methods}

\section{Chemicals}

The tested pesticide active ingredients are HCH-delta, endosulfan sulfate, $\mathrm{HCH}$-alpha, HCH-gamma (lindane), heptachlor, aldrin, HCH-beta, heptachlor epoxide, endosulfan I, 4,4-DDE, dieldrin, endrin, 4,4-DDD, endosulfan II, 4,4-DDT, endrin aldehyde, and methoxychlor, and were supplied by Varian Company. The organic solvent used was methylene chloride.

\section{Study Area and Sampling}

Three sites, located in Kafr El-Sheikh Governorate, Egypt, of agricultural water drainages ware selected for collection of water study samples, those are Nashart drainage, nine drainages and El-shoka drainage. Samples were taken manually $30 \mathrm{~cm}$ under the surface of the water and transported to the laboratory in an icebox according to the method of EPA (1995).

\section{Media}

Minimal medium as Mineral Salt Liquid (MSL) and Mineral Salt Agar Medium (MSA), Nutrient Agar Medium, and Nutrient Broth Medium, were used as enrichment media throughout this study. Nutrient agar medium is a product of OXOID with composition: Peptone $5 \mathrm{~g} / \mathrm{l}, \mathrm{NaCl} 5 \mathrm{~g} / \mathrm{l}$, Yeast extract $2 \mathrm{~g} / \mathrm{l}$, agar $15 \mathrm{~g} / \mathrm{l}$, and Distilled water $1000 \mathrm{ml}$. Nutrient broth medium with the composition of Peptone 5 $\mathrm{g} / \mathrm{l}, \mathrm{NaCl} 5 \mathrm{~g} / \mathrm{l}$, Yeast extract $2 \mathrm{~g} / \mathrm{l}$, and Distilled water 1000 ml. M9; Minimal Salts Liquid (MSL) 5X with composition of $\mathrm{KH}_{2} \mathrm{PO}_{4} 15 \mathrm{~g} / \mathrm{l} \mathrm{Na} 2 \mathrm{HPO} 433.9 \mathrm{~g} / \mathrm{l}, \mathrm{NaCl} 2.5 \mathrm{~g} / \mathrm{l}, \mathrm{NH} 4 \mathrm{Cl} 5 \mathrm{~g} / \mathrm{l}$, and Distilled water $1000 \mathrm{ml}$. M9; Mineral Salt Agar (MSA) 5X with composition of $\mathrm{KH}_{2} \mathrm{PO}_{4} 15 \mathrm{~g} / \mathrm{l} \mathrm{Na}_{2} \mathrm{HPO}_{4} 33.9 \mathrm{~g} / \mathrm{l}, \mathrm{NaCl}$ $2.5 \mathrm{~g} / \mathrm{l}, \mathrm{NH}_{4} \mathrm{Cl} 5 \mathrm{~g} / \mathrm{l}$, Agar $15 \mathrm{~g} / \mathrm{l}$, and Distilled water 1000 ml. BG-11 modified with composition of solutions A and $\mathrm{B}$, containing (in grams): A; NaHCO3, 11.61; Na2CO3, 3.53; K2HPO4, 0.5 dissolved in $500 \mathrm{ml}$ distilled water; B; NaNO3, 5 g; K2SO4, NaCl, 1; MgSO4 7H2O, 0.2; $\mathrm{CaCl} 2,0.04$ and $1 \mathrm{ml}$ EDTA (0.5 M). Micronutrient solution (CHU) consisted of the following trace metals (in milligrams) dissolved in one liter distilled water: Na2-EDTA, 50; H3BO3, 618; CuSO4 5H2O, 19.6; ZnSO4 7H2O, 44, CaCl2 6H2O, 20; $\mathrm{MnCl} 2,12$ and $\mathrm{Na} 2 \mathrm{MoO} 4$ 2H2O, 12.6. Solutions A and B were sterilized by autoclaving separately at $1211 \mathrm{C}$ for $20 \mathrm{~min}$. Micronutrient solution was sterilized by filtration through a $0.22-\mathrm{mm}$ polycarbonate membrane to avoid interaction precipitation of heavy metals.

\section{Isolation of the Bacterial Strains Capable of OCPs Biodegradation using Enrichment Culture Media}

Enrichment cultures of microorganisms capable of degrading chlorinated pesticides were established from the collected water samples of agricultural drainage water. Water samples were collected from three agricultural drains within Kafr El-Sheikh governorate, Egypt, and were previously tested for detecting chlorinated pesticide concentrations. A volume of $10 \mathrm{~mL}$ of each sample was suspended in 90 mL sterilized mineral salt medium (Appendix 6) in a 500$\mathrm{mL}$ bottle containing (100 ug/L) of chlorinated pesticide standard as a sole source of carbon and then incubated at 30 $\mathrm{C}$ and $150 \mathrm{r} / \mathrm{min}$ for 30 days. After that, a volume of $10 \mathrm{ml}$ of the cultures was transferred into a fresh $90 \mathrm{~mL}$ MSL medium containing the same concentration of chlorinated pesticides. This procedure was repeated four times. Dilution series were prepared after the final time from the enrichment culture in a glass tube containing $9 \mathrm{~mL}$ MSL medium up to $1 \cdot 10-6$, and then a volume of $100 \mu \mathrm{L}$ all of it was spread on plates of MSL medium chlorinated pesticides (100 ug/L) using Drigalski triangle. The plates were sealed in polyethylene bags, then incubated at $30{ }^{\circ} \mathrm{C}$ for 7 days and monitored for the appearance of colonies. Single colonies growing on these diluted plates were isolated by picking the colonies using sterile inoculation needle and were further purified by the standard spatial streaking on complex agar media for bacterial isolate (Derbalah et al., 2008; Massoud et al., 2008). 


\section{Screening of Chlorinated Pesticide Degrading Bacterial Isolates}

A total of 8 morphologically different chlorinated pesticide degrading bacterial isolates were obtained. The isolated colonies were tested for their ability to grow in MSL medium containing (10 ug/L) of the organochlorinated pesticide standard. One treatment contained the medium as well as pesticide standard, while the other contained the medium and the isolate as a control (no pesticides). The cultures were incubated at $30^{\circ} \mathrm{C}$ for 7 days. Screening of bacterial isolates that had the greater capability of degrading chlorinated pesticides was carried out depending on the viable count of bacterial isolates. Serial dilution tubes were prepared from each culture and then a volume of $100 \mathrm{uL}$ of each tube was spread on plates of plate count agar medium using a sterilized drigalisky triangle. Plates were further incubated at $30^{\circ} \mathrm{C}$ for 2 days, where the viable count of each strain was counted using a colony counter.

\section{Estimation of Biodegradation Capability of the Selected Isolates in the Aquatic System (liquid media)}

Inoculum preparation: Inocula used for the study were prepared by inoculating isolates into the nutrient broth and incubated at $30^{\circ} \mathrm{C}$ for $24 \mathrm{~h} .1 \mathrm{ml}$ of the culture of each selected isolate was used to inoculate each flask in the experiment.

\section{Biodegradation of OCPs by the Selected Bacterial Isolates in the Liquid Medium}

The most efficient four organochlorinated pesticide degrading bacterial isolates, as determined and recorded by the total viable count of bacterial isolates in the previous screening experiment, were further tested for their biodegradation capability for selecting the most biodegradative isolate. Mineral salts liquid media (MSL) was prepared, distributed into $250 \mathrm{ml}$ Erlenmeyer flasks each flask containing $50 \mathrm{ml}$ of the MSL and $(10 \mathrm{ug} / \mathrm{L})$ initial concentrations of the organochlorinated pesticide standard and then inoculated with $1 \mathrm{~mL}$ of culture containing $5^{*} 10^{6}$ $\mathrm{CFU} / \mathrm{mL}$ to study the biodegradation of OCPs in the aquatic system utilizing the four selected isolates. Another volume of the same medium (labeled as a control), containing the same concentration of OCPs, was incubated without being inoculated for detecting whether degradation of OCPs was due to the microbial activity or a result of other factors such as absorption into biomass. The cultures were further incubated at $30^{\circ} \mathrm{C}$ for 7 days.

\section{Growth Monitoring}

After the end of the incubation period, growth was monitored to evaluate the ability of each isolate to utilize OCPs as a sole source of carbon-based on two different ways, the turbidity of the culture medium at $600 \mathrm{~nm}$ using a spectrophotometer UV-VIS, in addition, the total viable count measurement for the cultures.

The growth represented in turbidity measurements was carried out by withdrawing a measured volume of each culture and reading it directly on spectrophotometer UV-VIS while the total viable count of each isolate was determined by plating the appropriate dilutions of the liquid medium onto nutrient agar medium and estimating the bacterial populations counting the number of colonies on plates.

\section{Determination of OCP Residues}

The percentage of degradation for the tested pesticides also was determined at the end of the incubation period after extracting the OCPs residues in the same way discussed above and analyzed by using Gas Chromatography model (Varian CP3800) equipped with an ECD for the detection of chlorinated pesticides to evaluate the biodegradation process.

\section{Extraction and Cleanup}

For each sample, $5 \mathrm{~g}$ of $25 \%$ anhydrous sodium sulfate was placed on standard Watman filter paper, $47 \mathrm{~mm}$, in a funnel, and the sample was filtered to retain all water. Then supernatant of the 5-ml sample was extracted twice with 50 $\mathrm{ml}$ methylene chloride $(1: 10 \mathrm{v} / \mathrm{v})$. The extract was filtered through an anhydrous sodium sulfate column, air-dried, and dissolved in $2 \mathrm{ml} \mathrm{n}$-hexane. Cleanup was carried out using a small chromatographic column $\left(25 \_2 \mathrm{~cm}\right)$ packed with florsil (PRg RAED, mesh size 6-100) preheated at 70 $1 \mathrm{C}$ for $24 \mathrm{~h}$ to remove moisture and prewashed with $50 \mathrm{ml}$ of 1M-methylene chloride. Half a milliliter of the sample and $0.5 \mathrm{ml}$ of $\mathrm{n}$-hexane were added to the column, followed by evaporated and concentrated using a micro-Snyder column fitted on a concentrator tube and the volume was adjusted to exactly $2.0 \mathrm{ml}$.

\section{Measurement of OCP Residues}

An aliquot ( $1 \mathrm{ml}$ ) was injected into the gas chromatograph equipped with a Hewlett Packard 6890 series II capillary with an electron capture detector (GC- ECD), on a DB-17 fused-silica capillary column $\left(30 \mathrm{~m} \_0.32 \mathrm{~mm} \_0.25 \mathrm{~mm}\right.$ film thickness). The injection took place at oven temperature 200 $1 \mathrm{C}$, injection temperature $2751 \mathrm{C}$, and ECD temperature 300 1C. Nitrogen (carrier) gas flow rate was $4 \mathrm{ml}$ min_1 OCPs were identified by comparing its gas chromatographic retention time (3.870.2 min) with that of a technical standard. The concentration of OCPs was calculated by comparing the total 
area of each detected peak with the total area of the standard pesticide.

Identification: The most efficient OCPs degrading bacterium isolate was identified based on morphological and biochemical characters and $16 \mathrm{~S}$ rRNA gene analyses.

\section{Morphological Characterization}

Morphological and cultural characterization of the selected isolate: Bacterial isolates were examined for their cell shape, motility studies, and gram reaction.

Cell shape: The purified cultures at the log phase after 72 hours were microscopically examined for the cell morphological characters.

Motility: The 72-hours grown isolates were microscopically examined using cavity slides for bacterial motility.

Gram reaction: Gram staining was carried out as mentioned by Rangaswami and Bagyaraj, (1993).

Biochemical characterization: Identification of all isolates was confirmed by secondary identification (Automated) using the Biomerieux Vitek 2 compact System according to Funke and Funke-Kissling (2004); Funke and Funke-Kissling (2005). A set of 64 biochemical characterizations tests were performed automatically for the efficiently selected isolate using VITEK 2 compact system, an automated microbiology system utilizing growth-based technology (AOAC OMA 2012.02) [28]. The Vitek 2 Compact (30 card capacity) system uses a fluorogenic methodology for organism identification and a turbidimetric method for susceptibility testing using a 64 well card that is barcoded with information on card type, expiration date, lot number, and unique card identification number. Test kits available include ID-GN (gram-negative bacillus identification), ID-GP (gram-positive cocci identification), AST-GN (gram-negative susceptibility) and AST-GP (gram-positive susceptibility). Technological advances made by the VITEK 2 Compact make it possible to report culture results faster.

Molecular characterization: The most efficient bacterial isolate regarding OCP degradation was identified using 16S rRNA as described by Boye, et al. (1999) [29]. DNA was extracted and purified using the protocol of GeneJet genomic DNA purification Kit (Thermo K0721), and polymerase chain reaction (PCR) was performed using Maxima Hot Start PCR Master Mix (Thermo K1051), then a PCR clean up to the PCR product was carried out using GeneJET PCR Purification Kit (Thermo K0701), Finally; sequencing to the PCR product was performed by use ABI 3730xl DNA sequencer by using forward and reverse primers through combining the traditional Sanger technology with the new 454 technology.

Phylogenetic Tree Construction: The nucleotide sequences were compared with those from the GenBank using BLASTn in the National Center for the Biotechnology Information server (http://www.ncbi.nlm.nih.gov). The sequence of PCR product and the reference sequences retrieved from the GenBank were aligned by ARB (http://www.arb-home.de) to construct the phylogenetic tree using the neighbor-joining method (based on Jukes-Cantor corrected distance). The bootstrap value was calculated based on 1,000 replications.

\section{Toxicity Evaluation of Remaining Chlorinated Pesticides after Remediation}

The bioassay of the remaining chlorinated pesticides was performed on the aqueous solutions using the cyanobacterial strain Anabaena sp. as the test organism. The toxicity was determined by monitoring the growth of Anabaena in terms of both chlorophyll a content and dry weight compared to control treatment (untreated). $100 \mathrm{ml}$ of sterilized BG11 cyanobacterial medium in $250-\mathrm{ml}$ conical flasks were prepared and sterilized. Each of the flasks was inoculated with $5 \mathrm{ml}$ of the 1-week dense individual cyanobacterial suspension; The cyanobacterial strain Anabaena sp. was inoculated into $50 \mathrm{ml}$ BG 11 culture medium and incubated for 1 week until heavy growth was obtained. Cultures were manually stirred twice for a few minutes every day. The cultures tested for pesticides toxicity were supplemented individually with $50 \mathrm{ul}$ of the supernatant of the pesticide degradation byproduct obtained by centrifuging the bacterial cultures which previously were incubated with the OCPs, while the control flasks contained the cyanobacterial culture supplemented with OCPs active ingredients to assess toxicological effects of the pesticides on Anabaena, after that all cultures were re-incubated and samples were collected after for the determination of cyanobacterial growth as toxicity markers. For the determination of chlorophyll a content, the cyanobacterial chlorophyll a content was extracted by methanol. $3 \mathrm{ml}$ of algal culture were centrifuged for $10 \mathrm{~min}$ at $10000 \mathrm{rpm}$, the supernatant was discarded, the same volume of methanol was added to the pellets, then the test tubes were incubated in water bath at $600 \mathrm{C}$ for $20 \mathrm{~min}$, and were centrifuged again then photosynthetic pigment was determined spectrophotometrically at the wavelength $650 \mathrm{~nm}$ and $665 \mathrm{~nm}$. The quantity of chlorophyll a content was determined by the equation introduced by Mackinny. For determination of dry weight, the culture samples was determined by drying the algal suspension at $100{ }^{\circ} \mathrm{C}$ in a drying oven for $24 \mathrm{~h}$ after being filtered through a pre dried and pre weighed $0.45 \mathrm{um}$ filter paper. 


\section{Results and Discussion}

\section{Isolation of the Bacterial Strains Capable of OCPs Biodegradation using Enrichment Culture Media}

The applying of the enrichment culture technique led to isolation of a total of eight morphologically different bacterial isolates having the potentiality to mineralize and degrade a set of 17 organochlorinated pesticides from three drainage water samples which were previously collected from the three preceding described agricultural water drainages. These results are in agreement with previous findings reported by Derbalah and Belal (2008), who found that enrichment culture technique led to the isolation of two bacterial strains, which were able to degrade cymoxanil pesticide rapidly in liquid cultures. The application of pesticides promotes the evolution of microorganisms that are capable of degrading these xenobiotic compounds in the water.

\section{Screening of Chlorinated Pesticide Degrading Bacterial İsolates}

The ability of the different eight tested isolates to grow on and degrade the defined concentration of OCPs residues was evaluated depending on the viable count of bacterial isolates. Table 1 represents the viable count of the eight bacterial isolates that have the capability to grow on and biodegrade chlorinated pesticides. The four bacterial isolates, Isolate No. 3 (01) Isolate No. 5 (02) Isolate No. 8 (N2) Isolate No. 9 (03) showed the highest count. The application of total viable count for Screening of chlorinated pesticide degrading bacterial isolates was also carried out by Belal, et al. [30].

\begin{tabular}{|c|c|c|}
\hline Code & Bacterial Isolates & Count (CFU/ml) \\
\hline 1 & Isolate No. 1 & $10 * 103$ \\
\hline 2 & Isolate No. 2 & $22 * 102$ \\
\hline 3 & Isolate No. 3 (01) & $30 * 106$ \\
\hline 4 & Isolate No. 4 & $15 * 103$ \\
\hline 5 & Isolate No. 5 (02) & $40 * 105$ \\
\hline 6 & Isolate No. 6 & $21 * 102$ \\
\hline 7 & Isolate No. 7 & $18^{*} 103$ \\
\hline 8 & Isolate No. 8 (N2) & $43 * 105$ \\
\hline 9 & Isolate No. 9 (O3) & $38^{*} 105$ \\
\hline
\end{tabular}

Table 1: Total Viable Count of the Bacterial Isolates.

\section{Biodegradation of OCPs by the Selected Bacterial Isolates in Liquid Medium}

The most efficient four organochlorinated pesticide degrading bacterial isolates, as determined and recorded by the total viable count of bacterial isolates in the previous screening experiment, were further tested for their biodegradation capability for selecting the most biodegradative isolates. Table 2 and Figure 1 shows the different growth findings in terms of viable count and optical density for the four OCPs degrading bacterial isolates. The four bacterial isolates recorded elevated growth rates indicating that the bacterial isolates were capable of growth and mineralization depending on the pesticides residues as a sole source of carbon. The bacterial isolate N2 showed significant increase in the total viable count and OD measurements. This elevated growth rate, represented in the total viable count and optical density, is indicating that the bacterial isolate $\mathrm{N} 2$ was capable of growth and mineralization depending on the pesticides residues as a sole source of carbon. The analysis of OCPs residues, using Gas Chromatography for the detection of pesticides removal percentage by the four tested bacterial isolates showed that the four bacterial isolates showed different biodegradation abilities as shown in table 3 and figures 2, 3, 4 and 5. The bacterial isolates were found to be superior degraders and/or removers of OCPs. They all recorded highly efficient degradation and/ or removal ability at the investigated concentrations. With regards to the finidings of the removal percentages. It was found that the bacterial isolate 02 documented dramatically biodegradation potential as shown by the GC findings of residual values of the tested pesticides, where it was found that the degradation percentage reached $100 \%$ for all the 17 tested pesticides.

\begin{tabular}{|c|c|c|}
\hline Bacterial isolates & Total Viable cout & OD (nm) \\
\hline & (CFU-ml) & \\
\hline $\mathrm{N} 2$ & $27^{*} 10^{9}$ & 0.027 \\
\hline 01 & $4^{*} 10^{9}$ & 0.018 \\
\hline 02 & $70^{*} 10^{9}$ & 0.076 \\
\hline 03 & $21^{*} 10^{9}$ & 0.012 \\
\hline
\end{tabular}

Table 2: The total viable count and the optical density of the Bacterial Isolate.

Biodegradation of OCPs was distinctly observed following incubation by the bacterial isolate N2. For nearly all OCPs; with only one exception, where there was a slight stepwise decrease in the removal efficiency percentage for Endosulfan II (64.3\%), the degradation percentage reached $100 \%$. 4,4'-DDD recorded a degradation percentage of 96.5 . Such complete degradation of most of the 17 OCPs was also pointed out by recent researchers [31]. Pan, et al. recorded the complete bacterial mineralization of DDT to its metabolites DDE/DDD, DDMU, DDOH, and DDA via dechlorination, hydroxylation, and carboxylation, and ultimately mineralized to carbon dioxide. For the biodegradation results by the 
bacterial isolate 03 , three OCPs were completely degraded, those are Aldrin, 4,4'-DDE and Methoxychlor, while the rest of the 17 OCPs exhibited variable and lower biodegradation abilities ranging from $98.5 \%$ of bioremoval for 4,4'-DDD to $51 \%$ for Endosulfan sulfate. In a comparison of the biodegradation potential of the bacterial isolate 01 with the other three ones, $\mathrm{N} 2,02$, and 03 , it is obviously noticed that the bacterial isolate 01 possessed the lowest overall degradation percentages. The obtained results exhibited that bacteria play a dominating role in organochlorine pesticide degradation. Our findings in the biodegradation process are in agreement with Abraham, and Silambarasan.

\begin{tabular}{|c|c|c|c|c|c|c|c|c|}
\hline \multirow{2}{*}{$\begin{array}{c}\text { Bacterial Isoaltes } \\
\text { OCPs }\end{array}$} & \multicolumn{2}{|l|}{01} & \multicolumn{2}{|l|}{$\mathbf{0 2}$} & \multicolumn{2}{|l|}{03} & \multicolumn{2}{|l|}{$\begin{array}{r}\mathrm{N} 2 \\
\end{array}$} \\
\hline & $\begin{array}{c}\begin{array}{c}\text { Residual } \\
\text { cocentration } \\
(\mu \mathrm{g} / \mathrm{L})\end{array} \\
\end{array}$ & $\begin{array}{c}\text { Removal } \\
\%\end{array}$ & \begin{tabular}{|c|}
$\begin{array}{c}\text { Residual } \\
\text { cocentration } \\
(\mu \mathrm{g} / \mathrm{L})\end{array}$ \\
\end{tabular} & $\begin{array}{c}\text { Removal } \\
\%\end{array}$ & $\begin{array}{c}\begin{array}{c}\text { Residuall } \\
\text { cocentration } \\
(\mu \mathrm{g} / \mathrm{L})\end{array} \\
\end{array}$ & $\begin{array}{c}\text { Removal } \\
\%\end{array}$ & $\begin{array}{c}\begin{array}{c}\text { Residual } \\
\text { cocentration } \\
(\mu \mathrm{g} / \mathrm{L})\end{array} \\
\end{array}$ & $\begin{array}{c}\text { Removal } \\
\%\end{array}$ \\
\hline HCH-alpha & 6.35 & 22 & 0 & 100 & 4.33 & 47 & 0 & 100 \\
\hline HCH-gamma & 3.9 & 55.6 & 0 & 100 & 4.88 & 45 & 0 & 100 \\
\hline Heptachlor & 1.6 & 80.6 & 0 & 100 & 1.43 & 82.3 & 0 & 100 \\
\hline Aldrin & 3.35 & 62.6 & 0 & 100 & 2.8 & 68 & 0 & 100 \\
\hline HCH-beta & 1.55 & 82.3 & 0 & 100 & 0.93 & 89.3 & 0 & 100 \\
\hline HCH-delta & 3.6 & 60.6 & 0 & 100 & 0 & 100 & 0 & 100 \\
\hline $\begin{array}{c}\text { Heptachlor } \\
\text { epoxide }\end{array}$ & 6.5 & 27.6 & 0 & 100 & 3.8 & 57.3 & 0 & 100 \\
\hline Endosulfan I & 1.36 & 85.3 & 0 & 100 & 3.23 & 65 & 0 & 100 \\
\hline 4,4'-DDE & 5.6 & 34.6 & 0 & 100 & 4.57 & 46.3 & 0 & 100 \\
\hline Dieldrin & 0.65 & 92.3 & 0 & 100 & 0 & 100 & 0 & 100 \\
\hline Endrin & 0.167 & 53 & 0 & 100 & 0.78 & 91 & 0 & 100 \\
\hline 4,4'-DDD & 1.1 & 86.6 & 0 & 100 & 0.28 & 96.3 & 0 & 100 \\
\hline Endosulfan II & 1.25 & 90.6 & 0 & 100 & 0.13 & 98.3 & 0.3 & 64.3 \\
\hline 4,4'-DDT & 0.85 & 86.3 & 0 & 100 & 1.13 & 87.3 & 0 & 100 \\
\hline Endrin aldehyde & 0 & 90.6 & 0 & 100 & 0.33 & 96.3 & 0 & 100 \\
\hline Endosulfan sulfate & 2.3 & 100 & 0 & 100 & 0 & 100 & 0 & 100 \\
\hline Methoxychlor & 1.55 & 72.3 & 0 & 100 & 2.87 & 65.3 & 0 & 100 \\
\hline
\end{tabular}

Table 3: Initial concentrations of OCPs, OCPs concentrations in control samples, and OCPs concentrations in the bacterial cultures at the end of the incubation periods.

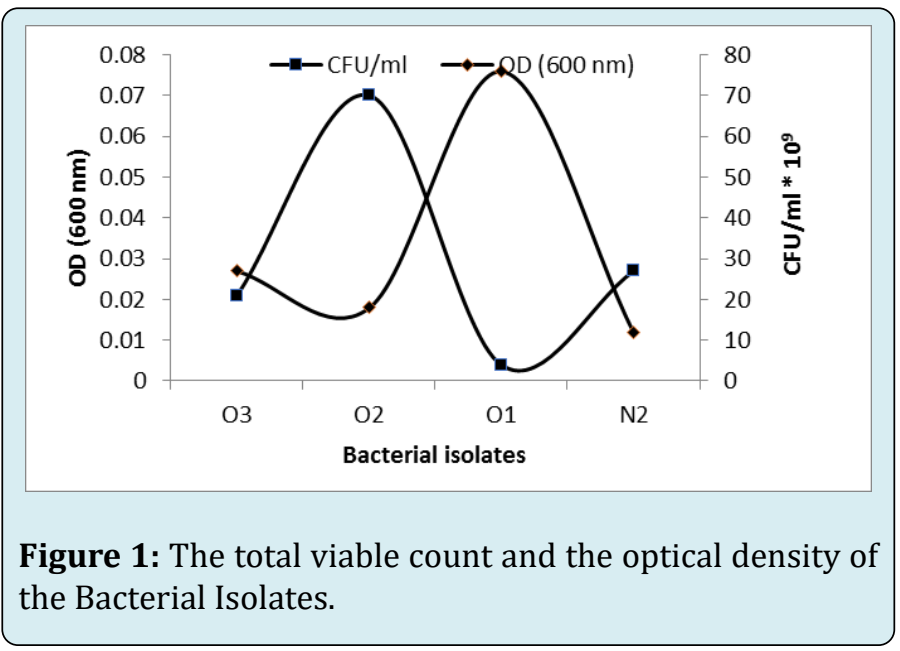

The control sample for OCPs showed a negligible changed concentration of the OCPs till the end of the experiment, meaning that OCP residues are persistent. One the other hand, the pesticides incubated with the microorganisms showed the lowest concentration of the residues in comparing with the initial concentrations that are obviously can be returned to the microbial action as discussed by Massoud, et al. (2008), Derbalah and Belal (2008) and Derbalah, et al. (2008). So among those 4 bacterial isolates, three bacterial isolates designated as $\mathrm{N} 2, \mathrm{O} 2$ and $\mathrm{O} 3$ exhibited higher OCPs removal comparing with the other isolates.

\section{Identification of One of the Most Efficient the Organochlorine Pesticides Degrading İsolates}

One of the most efficient OCPs degrading bacterial 
isolates; 03 was identified on the basis of morphological, biochemical characters and 16S rRNA gene analyses. The data in table 4 presents some of the morphological characteristics and gram staining results of the bacterial isolates 03 .

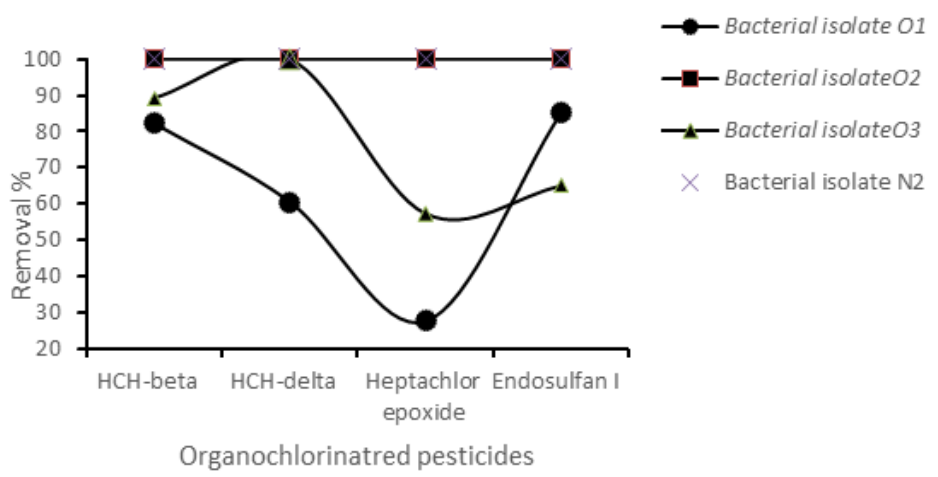

Figure 2: Biodegradation of organochlorinated pesticides (HCH-beta, HCH-delta, Heptachlor epoxide and Endosulfan I) by the four bacterial isolates $01,02,03$ and $\mathrm{N} 2$.

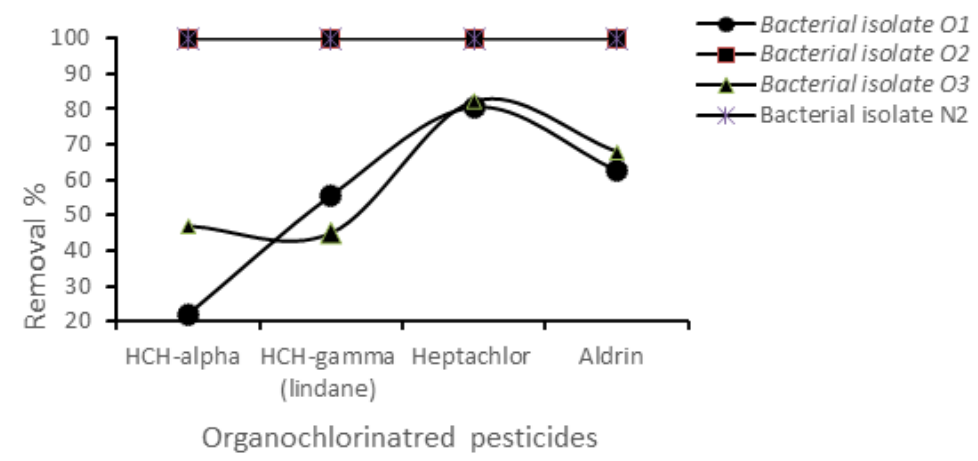

Figure 3: Biodegradation of organochlorinated pesticides (HCH-alpha, HCH-gamma (Lindane), Heptachlor and Aldrin) by the four bacterial isolates $01,02,03$ and $\mathrm{N} 2$.

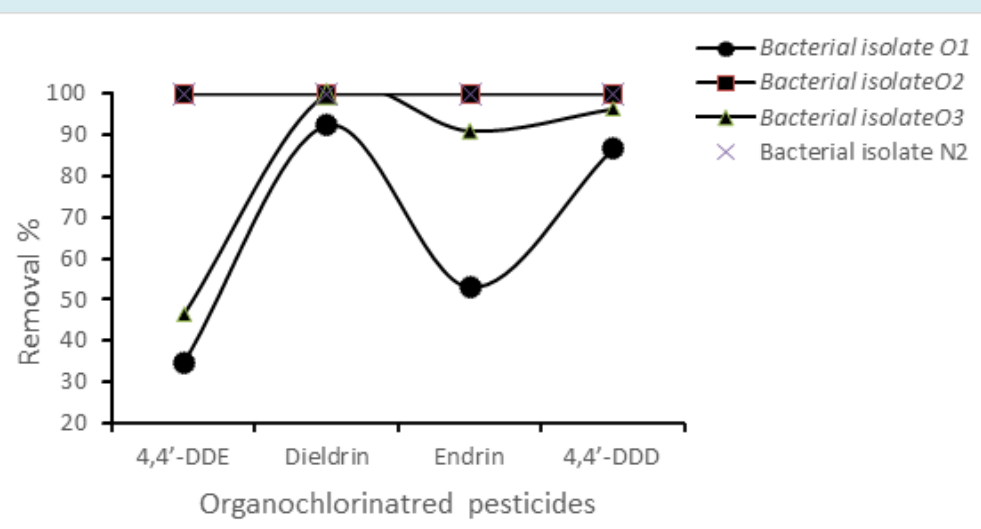

Figure 4: Biodegradation of organochlorinated pesticides (4,4'-DDE, Dieldrin, Endrin and 4,4'-DDD) by the four bacterial isolates $01,02,03$ and $\mathrm{N} 2$. 


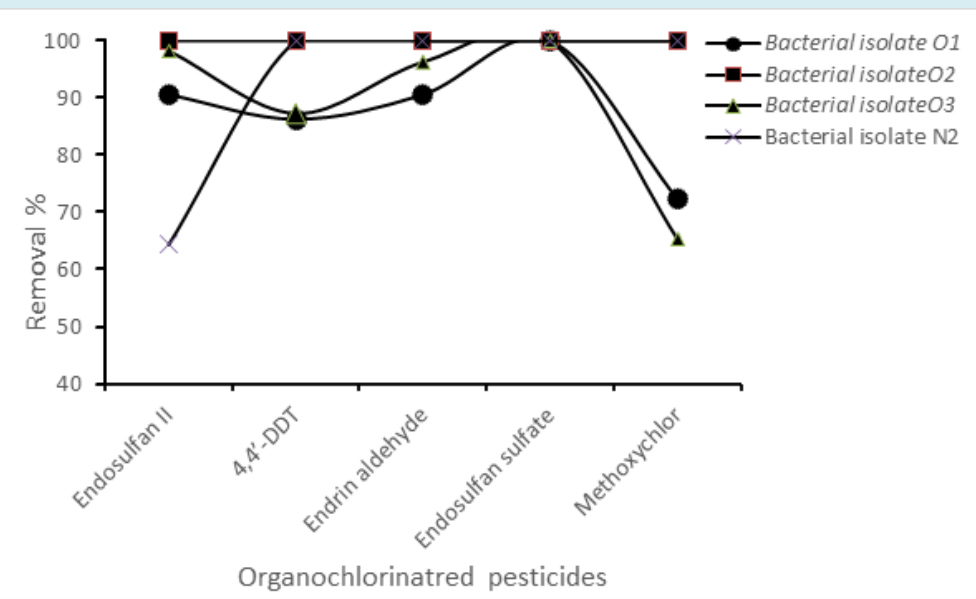

Figure 5: Biodegradation of organochlorinated pesticides (Endosulfan II, 4,4'-DDT, Endrin aldehyde, Endosulfan sulfate and Methoxychlor) by the four bacterial isolates 01, 02, 03 and N2.

\begin{tabular}{|c|c|c|}
\hline \multicolumn{2}{|c|}{ Isolate } & 03 \\
\hline No & Colony characteristics & Results \\
\hline 1 & Gram stain & Negative \\
\hline 2 & Cell shape & Rod-shaped \\
\hline 3 & Motility & Positive \\
\hline 4 & Color & Creamy \\
\hline 5 & Margin & Entire \\
\hline 6 & Elevation & Flat \\
\hline 7 & Texture & Smooth \\
\hline
\end{tabular}

The biochemical characterization tests performed for the efficient selected isolates 03 by means of VITEK 2 system, an automated microbiology system utilizing growthbased technology, by VITEK 2 GP Biochemical Identification method (AOAC OMA 2012.02) [28], revealed that the tested bacterial isolate 03 is Pectobacterium wasabiae with $93 \%$ probability. The results of the biochemical characterization tests as given by VITEK 2 system for the bacterial isolate 03 are presented in table 5 .

Table 4: Morphological characteristics of the colony of the most efficient OCPs degrading isolates ( N2), (O2) and (O3).

\begin{tabular}{|c|c|c|c|}
\hline Well & Test & Mnemonic & Result \\
\hline 2 & Ala-Phe-Pro-ARYLAMIDASE & APPA & - \\
\hline 3 & ADONITOL & ADO & - \\
\hline 4 & L-Pyrorolydonyl & PyrA & + \\
\hline 5 & L- ARABITOL & IARL & - \\
\hline 7 & D-CELLOBIOSE & dCEL & - \\
\hline 9 & BETA-GALACTOSIDASE & BGAL & - \\
\hline 10 & H2S PRODUCTION & H2S & + \\
\hline 11 & BETA-N-ACETYL GLUCOSAMINIDASE & BNAG & + \\
\hline 12 & Glutamyl Arylamidase pNA & AGLTp & - \\
\hline 13 & D-GLUCOSE & GGT & + \\
\hline 14 & GAMMA-GLUTAMYL-Transferase & OFF & + \\
\hline 15 & FEMENTATION/GLUCOSE & BGLU & + \\
\hline 17 & BETA-GLUCOSIDASE & & + \\
\hline
\end{tabular}




\begin{tabular}{|c|c|c|c|}
\hline 18 & D-MALTOSE & dMAL & - \\
\hline 19 & D-MANNITOL & dMAN & + \\
\hline 20 & D-MANNOSE & dMNE & + \\
\hline 21 & BETA-XYLOSIDASE & BXYL & - \\
\hline 22 & BETA-Alanine arylamidase pNA & BAlap & - \\
\hline 23 & L-Proline ARYLAMIDASE & ProA & + \\
\hline 26 & LIPASE & LIP & - \\
\hline 27 & PALATINOSE & PLE & + \\
\hline 29 & Tyrosine ARYLAMIDASE & TyrA & + \\
\hline 31 & UREASE & URE & - \\
\hline 32 & D-SORBITOL & dSOR & + \\
\hline 33 & SACCHAROSE/SUCROSE & SAC & + \\
\hline 34 & D-TAGATOSE & dTAG & - \\
\hline 35 & D-TREHALOSE & dTRE & + \\
\hline 36 & CITRATE(SODIUM) & CIT & + \\
\hline 37 & MALONATE & MNT & - \\
\hline 39 & 5-KETO-D-GLUCONATE & $5 \mathrm{KG}$ & + \\
\hline 40 & L-LACTATE assimilation & ILATk & + \\
\hline 41 & ALPHA-GLUCOSIDASE & AGLU & + \\
\hline 42 & SUCCINATE alkalinisation & SUCT & + \\
\hline 43 & Beta-N-ACETYL-GALACTOSAMIDNIDASE & NAGA & + \\
\hline 44 & ALPHA-GALACTOSIDASE & AGAL & + \\
\hline 45 & PHOSPHATASE & PHOS & - \\
\hline 46 & Glycine ARYLAMIDASE & GlyA & + \\
\hline 47 & ORNITHINE DECARBOXYLASE & ODC & + \\
\hline 48 & LYSINE DECARBOXYLASE & LDC & + \\
\hline 53 & L-HISTIDINE assimilation & IHISa & - \\
\hline 56 & COUMARATE & CMT & + \\
\hline 57 & BETA-GLUCORONIDASE & BGUR & - \\
\hline 58 & 0/129 RESISTANCE & 0129R & + \\
\hline 59 & Glu-Gly-Arg-ARYLAMIDASE & GGAA & + \\
\hline 61 & L-MALATE assimilation & IMLTa & - \\
\hline 62 & ELLMAN & ELLM & - \\
\hline 64 & L-LACTATE assimilation & ILATa & - \\
\hline
\end{tabular}

Table 5: Biochemical identification of the bacterial isolate 03 using Biomerieux Vitek.

According to the 16S rRNA analysis [29], the phylogenetic tree of the OCPs degrading bacteria $\mathrm{O} 3$ are provided in figures 6 . It can be clearly seen that the bacterial isolate 03 was included in the genus pectobacterium and closely related to the species wasabiae, it also showed the highest sequence similarities with Pectobacterium wasabiae strain CFBP 3304. 


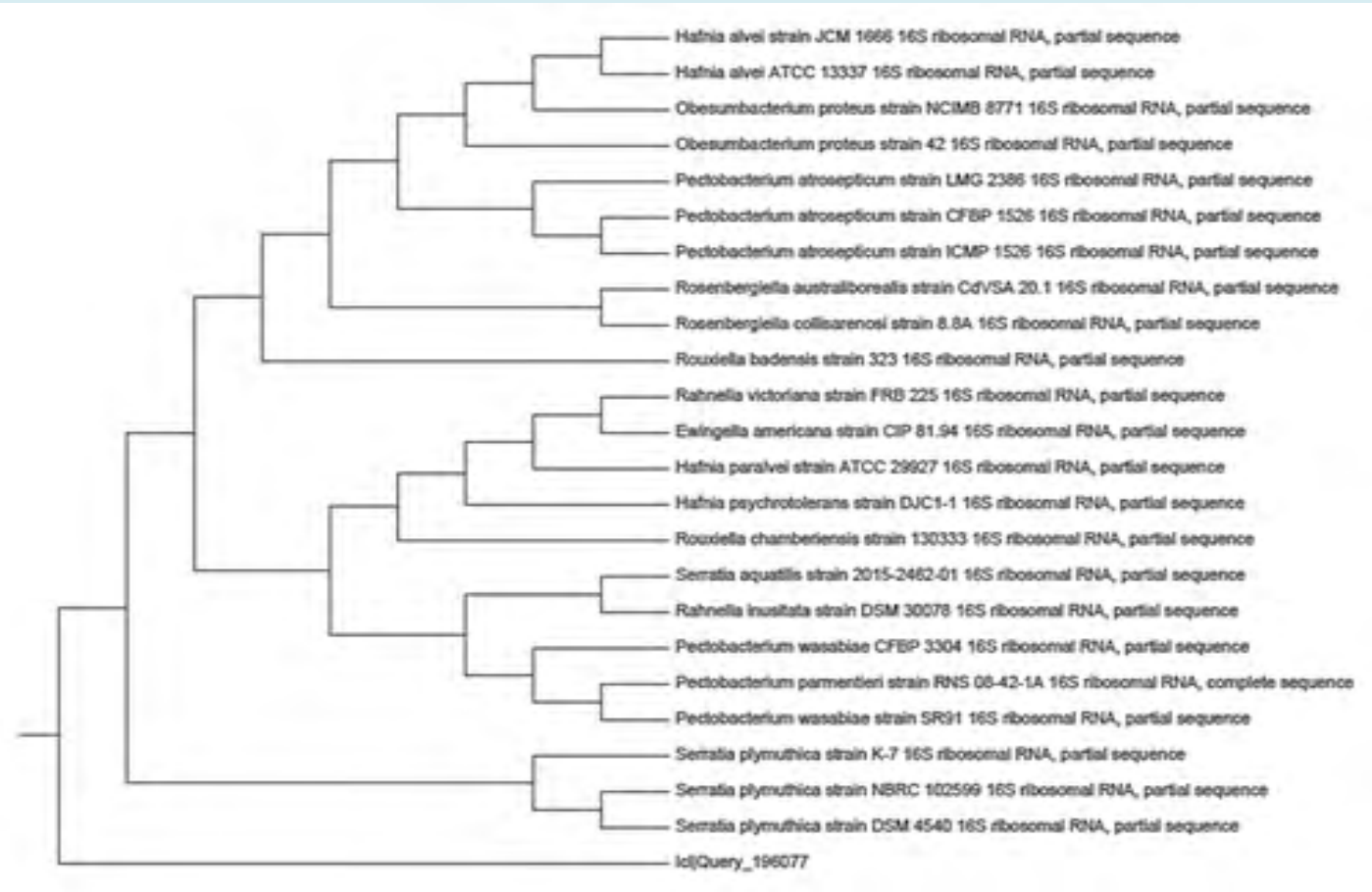

Figure 6: Phylogenetic dendrogram obtained by distance matrix analysis of $16 \mathrm{~S}$ rRNA sequences, showing the position of strain Pectobacterium wasabiae sp. (03) among phylogenetic neighbor.

\section{Toxicity of Remaining Chlorinated Pesticides on Anabaena as a Test Organism}

Though the bacterial treatment of pesticides contaminated- wastewater is very effective, it is found that microorganisms used in bacterial treatment processes can transform the pesticides into compounds, which are more toxic than of parent compounds. Hence, there was a need to study the toxic effects of the products formed after the biological treatment processes. Toxicity of the remaining chlorinated pesticides in the aqueous solution after 4 days of incubation with the tested microbial strain was evaluated using the cyanobacterial strain Anabaena sp. as a test organism. The growth was monitored in terms of chlorophyll a content and dry weight. The results presented in table 6 showed that the remaining pesticide concentrations after 4 days of incubation with the bacterial strain Pectobacterium wasabiae CFBP 3304 (03) had no toxicity as can be detected by observed Anabaena growth on media with presences of chlorinated pesticides degradation supernatant this reflects no inhibition of the strain and thus complete detoxification. The obtained results were compared with control treatment (pesticides without bacterial inoculation) which revealed higher values of inhibition against Anabaena under the same conditions as can be detected.

\begin{tabular}{|c|c|c|}
\hline $\begin{array}{c}\text { Dry } \\
\text { weight(mg/l) }\end{array}$ & $\begin{array}{c}\text { Ch a content } \\
\text { (mg/l) }\end{array}$ & Bacterial strains \\
\hline 82.5 & 2.151 & E. asburiae JCM6051 \\
\hline 128.3 & 1.481 & H. alvei ATCC13337 \\
\hline 213.3 & 1.278 & P. wasabiae CFBP3304 \\
\hline 30.4 & 1.397 & Control 1 \\
\hline
\end{tabular}

Table 6: Toxicity of remaining chlorinated pesticides against Anabaena as a test organism after treating with different tested microbial isolates.

These results have revealed that the degradation products were less toxic than pesticides for the microorganisms studied. This implies that the aqueous solution spiked with chlorinated pesticides was completely detoxified by treating with the bacterial strain Pectobacterium wasabiae CFBP 3304 (03). This inhibitory effect of OCPs on cyanobacterial growth could be attributed to the adsorption of these compounds on the rich-lipid plasma membranes of the algal cells, thus, altering the permeability of the membrane [32] and diminishing photosynthetic activity [33,34], as well as increasing reactive oxygen species (ROS) during stress [35]. These findings are in agreement with several previously published data [36-38]. A similar inhibitory effect of algal 
growth was reported for Scenedesmus obliqnus and Chlorella pyrenoidosa [39]; Chlorella kesslerei and Anabaena inaequalis. Cycon and Piotrowska-Seget, (2007) [40] referred to that pesticides might affect microorganisms by reducing their numbers, biochemical activity, diversity and influencing the community structure. Gaherwal, et al. [41] confirmed that the pesticide 2, 4-D, Dimethoate, and Carbendazim inhibit the growth of soil microorganism as nitrogen-fixing bacteria after 48, 72 and 96 hours.

\section{Conclusion}

The aim of the study was to, isolate some bacterial strains having the biodegradation capability of organochlorinated pesticides, screen the biodegradation potential of some bacterial strains and identify one the most efficient strain and to confirm the complete detoxification of the tested OCPs by measuring the toxicity of the treated solution against a sensitive target for the purpose of bioremediation application in severe OCPs contaminated water drainage. the ability for biodegradation and mineralization of different organochlorinated pesticides was observed markedly at varying percentages. The morphological, biochemical, and molecular characterization of bacterial strains was used for the identification of one the most effective strain as Pectobacterium wasabiae CFBP 3304 in biodegrading tested compounds. Toxicity evaluation of the remaining chlorinated pesticides in the aqueous solution with the tested microbial strain was evaluated using the cyanobacterial strain Anabaena sp. as a test organism showed that the remaining pesticide concentrations after 4 days of incubation with the bacterial strain Pectobacterium wasabiae CFBP 3304 (O3) had no toxicity as can be detected by observed Anabaena growth. These results have revealed that the degradation products were less toxic than pesticides for the microorganism studied. This study may be a key step in the biodegradation of active pesticide compounds and thus provide a major mechanism for bioremediation in the studied regions and other related regions.

\section{References}

1. Anju A, Ravi SP, Bechan S (2010) Water pollution with special reference to pesticide contamination in India. Journal of Water Resource and Protection 2(5): 432-448.

2. Chekroun KB, Sánchez E, Baghour M (2014) The role of algae in bioremediation of organic pollutants. Semantic Scholar.

3. Khan N, Hussain ST, Saboor A, Jamila N, Su Kim K (2013) Physiochemicalinvestigation of the drinking water sources from Mardan,Khyber Pakhtunkhwa, Pakistan. International journal ofphysical sciences 8(33): 16611671.
4. Pawari MJ, Gawande SAGAR (2015) Ground water pollution \& its consequence. International journal of engineering research and general science 3(4): 773-776.

5. Ullah H, Ahmed E, Ikram M (2014) Monitoring of glucose levels in mouse blood with noninvasive optical methods. Laser Physics 24(2): 025601.

6. Garcia AM (2003) Pesticide exposure and women's health. American journal of industrial medicine 44(6): 584-594.

7. Maksymiv IV, Husak VV, Mosiichuk NM, Matviishyn TM, Sluchyk IY, et al. (2015) Hepatotoxicity of herbicide Sencor in goldfish may result from induction of mild oxidative stress. Pesticide biochemistry and physiology 122: 67-75.

8. Abdel-Aty AM, El-Dib MA (2016) Changes in the community structure and growth of fresh water microalgae as a consequence of diuron exposures. Int J Chem Tech Res 9(8): 114-122.

9. Konstantinou IK, Hela DG, Albanis TA (2006) The status of pesticide pollution in surface waters (rivers and lakes) of Greece. Part I. Review on occurrence and levels. Environmental Pollution 141(3): 555-570.

10. Kole RK, Banerjee H, Bhattacharyya A (2001) Monitoring of market fi sh samples for Endosulfan and Hexachlorocyclohexane residues in and around Calcutta. Bull Envirron Contam Toxicol 67: 554-559.

11. Waliszewski S, Meza V, Infanzón R, Trujillo PY, Morales Guzmán I (2003) Niveles de plaguicidas organoclorados persistentes enmujeres con carcinoma mamario en Veracruz. Rev Int Contam Ambient 19(2): 59-65.

12. Kannan K, Tanabe S, Williams RJ, Tatsukawa R (1994) Persistant organochlorine residues in foodstuffs from Australia, Papua New Guinea and the Solomon Islands: Contamination levels and human dietary exposure. Sci Total Environ 153(1): 29-49.

13. Briz V, Molina-Molina JM, Sanchez-Redondo S, Fernandez MF, Grimalt JO, et al. (2011) Differential estrogenic eff ects of the persistent organochlorine pesticides dieldrin, endosulfan and lindane in primary neuronal cultures. Toxicological Sciences 120(2): 413-427.

14. USEPA (2010) Endosulfan. The Health Eff ects Divion's Human Health Risk Assessment, EPA DP Barcode: D372569. June 2010. Docket No.: EPAHQOPP-2002-0262-0178.

15. Sohail E, Waseem A, Chae WL, Jong JL, Imitiaz H (2004) Endocrine Disrupting Pesticides: A Leading Cause of 
Cancer among Rural People in Pakistan. Experimental Oncology 26(2): 98-105.

16. Kaiser J (2000) Endocrine disrupters: Panel cautiously confi rms low-dose effects. Science 290(5492): 695-697.

17. Singh BK, Kuhad RC, Singh A, Lal R, Tripathi KK (1999) Biochemical and molecular basis of pesticide degradation by 467 microorganisms. Critical reviews in biotechnology 19(3): 197-225.

18. Verma JP, Jaiswal DK, Sagar R (2014) Pesticide relevance and their microbial degradation: a-state-of-art. Reviews in Environmental Science and 470 Bio/Technology 13(4): 429-466.

19. Sinha M, Peterson CL (2009) Chromatin dynamics during repair of chromosomal DNA double-strand breaks. Epigenomics 1(2): 371-385.

20. Belal EB, Zidan NA, Mahmoud HA, Eissa FI (2008) Bioremediation of pesticides-contaminated soils. Journal of Agricultural Research, Kafrelsheikh Univ 34: 588-608.

21. MacRae IC (1989) Microbial metabolism of pesticides and structurally related compounds. In Reviews of Environmental Contamination and Toxicology. New York, Springer, pp: 1-87.

22. Lal R, Saxena DM (1982) Accumulation, metabolism, and effects of organochlorine insecticides on microorganisms. Microbiological reviews 46(1): 95-127.

23. Johnsen RE (1967) DDT metabolism in microbial systems. Residue Reviews 61: 1-28.

24. Sahasrabudhe SR, Modi VV (1987) Microbial degradation of chlorinated aromatic compounds. Microbiological Sciences 4(10): 300-303.

25. Barragán-Huerta BE, Costa-Pérez C, Peralta-Cruz J, Barrera-Cortés J, Esparza-García F, et al. (2007) Biodegradation of organochlorine pesticides by bacteria grown in microniches of the porous structure of green bean coffee. International Biodeterioration \& Biodegradation 59(3): 239-244.

26. Sonkong K, Prasertsan P, Sobhon V (2008) Screening and identification of $\mathrm{p}, \mathrm{p} \$$-DDT degrading soil isolates. Journal of Science and Technology 30(S1): 103-110.

27. Ahtiainen J, Valo R, Järvinen M, Joutti A (2002) Microbial toxicity tests and chemical analysis as monitoring parameters at composting of creosote-contaminated soil. Ecotoxicology and Environmental Safety 53(2): 323-329.
28. Crowley E, Bird P, Fisher K, Goetz K, Boyle M, et al. (2012) Evaluation of the VITEK 2 gram positive (GP) microbial identification test card: collaborative study. Journal of AOAC International 95(5): 1425-1432.

29. Boye K, Hogdall E, Borre M (1999) Identification of bacteria using two degenerate 16s rDNA sequencing primers. Microbiol Res 154(1): 23-29.

30. Belal ESB, Shalaby ME, El-Gremi SM, Gad WA (2018) Biodegradation of Organochlorine Pesticides by Paenibacillus sp. Strain. Environmental Engineering Science 35(11): 1194-1205.

31. Huang Y, Wang J (2013) Degradation and mineralization of DDT by the ectomycorrhizal fungi, Xerocomus chrysenteron. Chemosphere 92(7): 760-764.

32. Rioboo C,GonzálezO,Herrero C,CidA(2002) Physiological response of freshwater microalga (Chlorella vulgaris) to triazine and phenylurea herbicides. Aquatic Toxicology 59(3-4): 225-235.

33. Yamamoto Y, Tsukada H (2009) Measurement of in situ specific growth rates of microcystis (cyanobacteria) from the frequency of dividing cells (1). Journal of phycology 45(5): 1003-1009.

34. Manikar N, Kumar S, Habib K, Fatma T (2013) Biochemical analysis of Anabaena variabilis exposed to malathion pesticide with special reference to oxidative stress and osmolytes. International Journal of Innovative Research in Science, Engineering and Technology 2(10): 5403-5420.

35. Mostafa FI, Helling CS (2002) Impact of four pesticides on the growth and metabolic activities of two photosynthetic algae. Journal of Environmental Science and Health, Part B 37(5): 417-444.

36. Hammouda HE (1994) Inhibition of ammonium and nitrate uptake by trichlorfon in Gloeocapsa sp. Mans Sci Bull (B. Biology) 21(1): 87.

37. Seguin F, Leboulanger C, Rimet F, Druart JC, Bérard A (2001) Effects of atrazine and nicosulfuron on phytoplankton in systems of increasing complexity. Archives of environmental contamination and toxicology 40(2): 198-208.

38. El-Bestawy EA, El-Salam AZA, Mansy AERH (2007) Potential use of environmental cyanobacterial species in bioremediation of lindane-contaminated effluents. International Biodeterioration \& Biodegradation 59(3): 180-192.

39. Ma J, Zheng R, Xu L, Wang S (2002) Differential sensitivity 
of two green algae, Scenedesmus obliqnus and Chlorella pyrenoidosa, to 12 pesticides. Ecotoxicology and Environmental Safety 52(1): 57-61.

40. Cycon M, Piotrowska-Seget Z (2007) Effect of selected pesticides on soil microflora involved in organic matter and nitrogen transformations: pot experiment. Polish
Journal of Ecology 55: 207-220.

41. Gaherwal SM, Prakash K Khasdeo, Anirudh Sharma (2015) Impact of Selected Chemical and Herbal Pesticide on Beneficial Soil Microorganism. International Journal of Microbiological Research 6(3): 236-239. 